\title{
Prediction of Prehypertenison and Hypertension Based on Anthropometry, Blood Parameters, and Spirometry
}

\author{
Byeong Mun Heo ${ }^{1}$ (I) and Keun Ho Ryu ${ }^{2,3, *(\mathbb{D})}$ \\ 1 Database/Bioinformatics Laboratory, Chungbuk National University, Cheongju 28644, Korea; \\ muni4344@gmail.com \\ 2 Faculty of Information Technology, Ton Duc Thang University, Hochiminh City 700000, Vietnam \\ 3 Department of Computer Science, Chungbuk National University, Cheongju 28644, Korea \\ * Correspondence: khryu@tdtu.edu.vn or khryu@chungbuk.ac.kr; Tel.: +82-10-4930-1500
}

Received: 24 October 2018; Accepted: 14 November 2018; Published: 16 November 2018

\begin{abstract}
Hypertension and prehypertension are risk factors for cardiovascular diseases. However, the associations of both prehypertension and hypertension with anthropometry, blood parameters, and spirometry have not been investigated. The purpose of this study was to identify the risk factors for prehypertension and hypertension in middle-aged Korean adults and to study prediction models of prehypertension and hypertension combined with anthropometry, blood parameters, and spirometry. Binary logistic regression analysis was performed to assess the statistical significance of prehypertension and hypertension, and prediction models were developed using logistic regression, naïve Bayes, and decision trees. Among all risk factors for prehypertension, body mass index (BMI) was identified as the best indicator in both men [odds ratio $(\mathrm{OR})=1.429,95 \%$ confidence interval $(\mathrm{CI})=1.304-1.462)]$ and women $(\mathrm{OR}=1.428,95 \% \mathrm{CI}=1.204-1.453)$. In contrast, among all risk factors for hypertension, $\mathrm{BMI}(\mathrm{OR}=1.993,95 \% \mathrm{CI}=1.818-2.186)$ was found to be the best indicator in men, whereas the waist-to-height ratio ( $\mathrm{OR}=2.071,95 \% \mathrm{CI}=1.884-2.276)$ was the best indicator in women. In the prehypertension prediction model, men exhibited an area under the receiver operating characteristic curve (AUC) of 0.635 , and women exhibited a predictive power with an AUC of 0.777. In the hypertension prediction model, men exhibited an AUC of 0.700, and women exhibited an AUC of 0.845. This study proposes various risk factors for prehypertension and hypertension, and our findings can be used as a large-scale screening tool for controlling and managing hypertension.
\end{abstract}

Keywords: machine learning; feature selection; hypertension; prehypertension; anthropometry; spirometry

\section{Introduction}

Hypertension is a major disease burden worldwide and an important risk factor for cardiovascular disease (CVD), chronic kidney disease (CKD) and death [1-7], and prehypertension is also a risk factor that can lead to CVD, stroke and CKD [8-11]. Hypertension is highly associated with poor diet, low physical activity and excessive alcohol consumption $[7,12]$. The treatment of hypertension reduces the risk of stroke, coronary artery disease, and congestive heart failure [1].

Methods for managing hypertension include antihypertensive therapy and exercise therapy. Antihypertensive therapy reduces the mortality rates associated with stroke, myocardial infarction, CVD and heart failure [13-17], and exercise therapy is effective for lowering systolic blood pressure (SBP), diastolic blood pressure (DBP), and the levels of total cholesterol (TC), low-density lipoprotein cholesterol (LDL-C), triglyceride (TG) and high-density lipoprotein cholesterol (HDL-C) [18-22]. 
The obesity indices have been mainly used in association studies with hypertension. For example, waist circumference (WC) is a risk factor for hypertension in African populations, Caribbean populations, Brazilian women, and Filipina women [23-26]. The body mass index (BMI) is a risk factor for hypertension in China, the Philippines, the United States (US), Australian women and India [27-29]. The WC ratio (WHR) is associated with hypertension in Chinese women in Hong Kong and in Australian men [29,30], and the waist-to-height ratio (WHTR) is the best indicator of hypertension in Chinese men in Hong Kong [30], a Taiwanese population [31] and a Korean population [32]. WC, BMI, and WHR are also associated with prehypertension in a Taiwanese population [33].

Several published studies have investigated blood parameters and hypertension. For example, compared with normotensive individuals, hypertensive patients show higher levels of fasting plasma glucose, serum high-sensitivity C-reactive protein (hs-CRP), TG, TC, LDL-C, uric acid (UA), white blood cells (WBCs), red blood cells (RBCs), hemoglobin (HGB), hematocrit (HCT) and mean corpuscular hemoglobin and lower serum HDL-C, mean corpuscular volume and RBC distribution width $[34,35]$. A higher glycated hemoglobin $(\mathrm{HbA} 1 \mathrm{c})$ level is correlated with a higher prevalence of hypertension [36], and inadequate hypertension treatment elevates serum creatinine level [37]. Markers of inflammation (CRP, WBC, amyloid-a, and homocysteine) are present at high levels in men and women with prehypertension [38].

In previous studies of spirometry and hypertension, the forced vital capacity (FVC) was identified as a negative predictor of hypertension, and lower FVC values were found to be a risk factor for future hypertension $[39,40]$. In studies of Beijing and Guangzhou populations, the FVC and forced expiratory volume in $1 \mathrm{~s}$ (FEV1) were found to be inversely proportional to SBP and DBP in women in both populations and in men in Beijing. A follow-up study conducted 2 or 4 years later showed a low incidence of hypertension with low lung function, but this effect was found only in Guangzhou women [41]. In Swedish men aged 55-68 years, BP increased with decreasing FVC. A lower FEV1 was correlated with higher SBP and DBP [42].

Previous studies have reported the associations of anthropometry, blood parameters, and spirometry with hypertension or prehypertension, but no studies have yet described the relationships between each of prehypertension and hypertension and anthropometric indices, blood parameters, and spirometric indices. The purposes of this study are to analyze risk factors of hypertension and prehypertension and to present a machine-learning-based prediction model to reduce the risks of diseases (CVD, CKD, stroke) caused by hypertension and to prevent diseases. First, we present risk factors for hypertension and prehypertension with statistical significance using demographic indices, anthropometric indices, blood parameters, and spirometric indices. Second, we develop predictive models of hypertension and prehypertension based on machine learning using correlation-based feature selection (CFS) and wrapper-based feature selection (WFS) methods and logistic regression (LR), naïve Bayes (NB), and decision tree (DT) prediction algorithms. Last, we propose the best hypertension and prehypertension prediction model through the performance evaluation between the developed prediction models. To the best of our knowledge, this study provides the first demonstration of the associations of prehypertension and hypertension with obesity indices, blood parameters, and spirometric indices in a Korean population. The findings of the present study provide basic information for the treatment and prevention of prehypertension and hypertension.

\section{Materials and Methods}

\subsection{Subjects and Dataset}

We obtained data from the sixth Korea National Health and Nutrition Examination Survey (KNHANES VI). The KNHANES database is publicly available at the KNHANES website (http:/ / knhanes.cdc.go.kr/knhanes/eng). In this study, demographics, anthropometric indices, blood parameters and spirometric indices from the KNHANES VI were analyzed. KNHANES was approved by the Institutional Review Board of the Korea Centers for Disease Control \& Prevention (KCDC) 
and the KCDC Bioethics Committee. Informed consent was obtained from all the participants prior to KNHANES data collection (Approval Numbers: 2013-07CON-03-4C, 2013-12EXP-03-5C and 2015-01-02-6C).

The total number of subjects was 22948. According to the exclusion criteria, we performed the following:

- We selected 12,838 individuals after excluding 10110 participants under 40 years of age.

- We excluded 4626 patients with missing values (FVCP, $n=4008$; HDL-C, $n=585$; HbA1c, $n=30$;

WC, $n=1$; and hypertension diagnosis, $n=2$ ).

In total, 8212 subjects were included in the study. According to the definitions of hypertension, 3035 subjects with normal blood pressure, 2002 subjects with prehypertension and 3175 subjects with hypertension were classified (the details of the data preprocessing are provided in Figure 1).

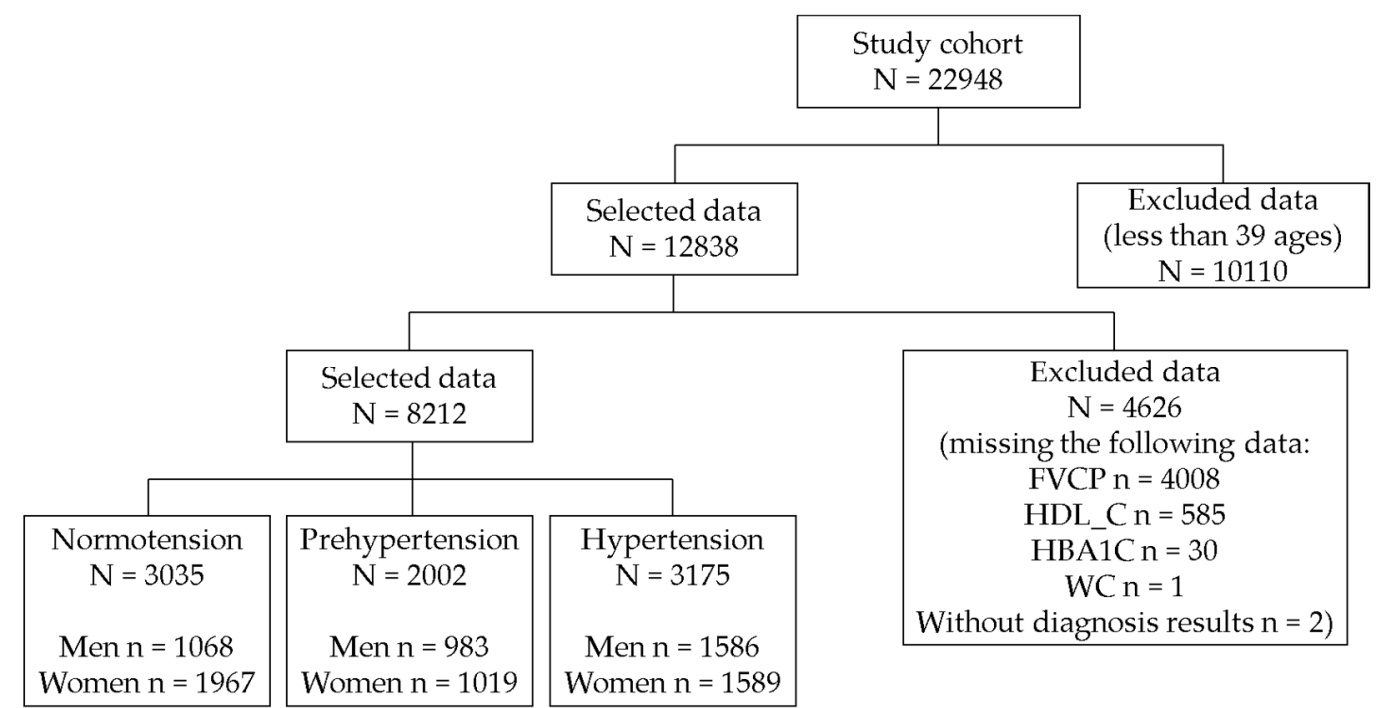

Figure 1. Sample selection procedure.

\subsection{Definitions of Prehypertension and Hypertension}

We used the criteria proposed by the World Health Organization (WHO) [5], the Joint National Committee 7 (JNC 7) [43] and previous studies to define normotension, prehypertension and hypertension $[8,10,11,33,44,45]$. Normotension was defined as an SBP less than $120 \mathrm{mmHg}$ and a DBP less than $80 \mathrm{mmHg}$. Prehypertension was defined as an SBP between $120 \mathrm{mmHg}$ and $139 \mathrm{mmHg}$ and a DBP between $80 \mathrm{mmHg}$ and $89 \mathrm{mmHg}$. Hypertension was defined as an SBP of at least $140 \mathrm{mmHg}$ and/or a DBP of at least $90 \mathrm{mmHg}$ [43], a diagnosis of hypertension or reported use of antihypertensive medications [11].

\subsection{Statistical Analysis}

Statistical analyses were performed using SPSS 20 for Windows (SPSS Inc., Chicago, IL, USA). Binary logistic regression (LR) was conducted to identify significant differences between normotension and prehypertension and between normotension and hypertension after standardized transformation was applied to the male and female datasets. Independent two-sample t-tests were used to examine the differences between men and women (basic characteristics are described in Table 1). We developed prehypertension and hypertension prediction models using the Waikato Environment for Knowledge Analysis data mining tool. The prediction models were developed using LR, naïve Bayes (NB), and decision tree (DT) classification algorithms, all of which are widely used classification models. The NB classifier uses Bayes' theorem and conditional probability to measure the probability of 
occurrence between classes and attributes and has the advantage of low computational cost [46]. The DT classifier creates an attribute with high information gain as an upper node based on entropy. Specifically, this classifier recursively creates an optimal tree structure by partitioning followed by pruning. DT has the advantages of being easy to understand, providing a visual tree structure and having low calculation cost [47]. LR classifiers are used extensively in medical statistical surveys because the results of analyses relating categorical dependent variables and one or more independent variables are easily interpreted. Depending on the number of dependent variables, a binary or polynomial model may be used [46]. To select the features associated with prehypertension and hypertension, correlation-based feature selection (CFS) and wrapper-based feature selection (WFS) were applied. CFS solves the multicollinearity problem to recommend a variable with low correlation between attributes and high correlation between attribute and class [48], and WFS selects variables through black-box testing using a classification algorithm [49].

Table 1. Basic characteristics of the subjects included in this study.

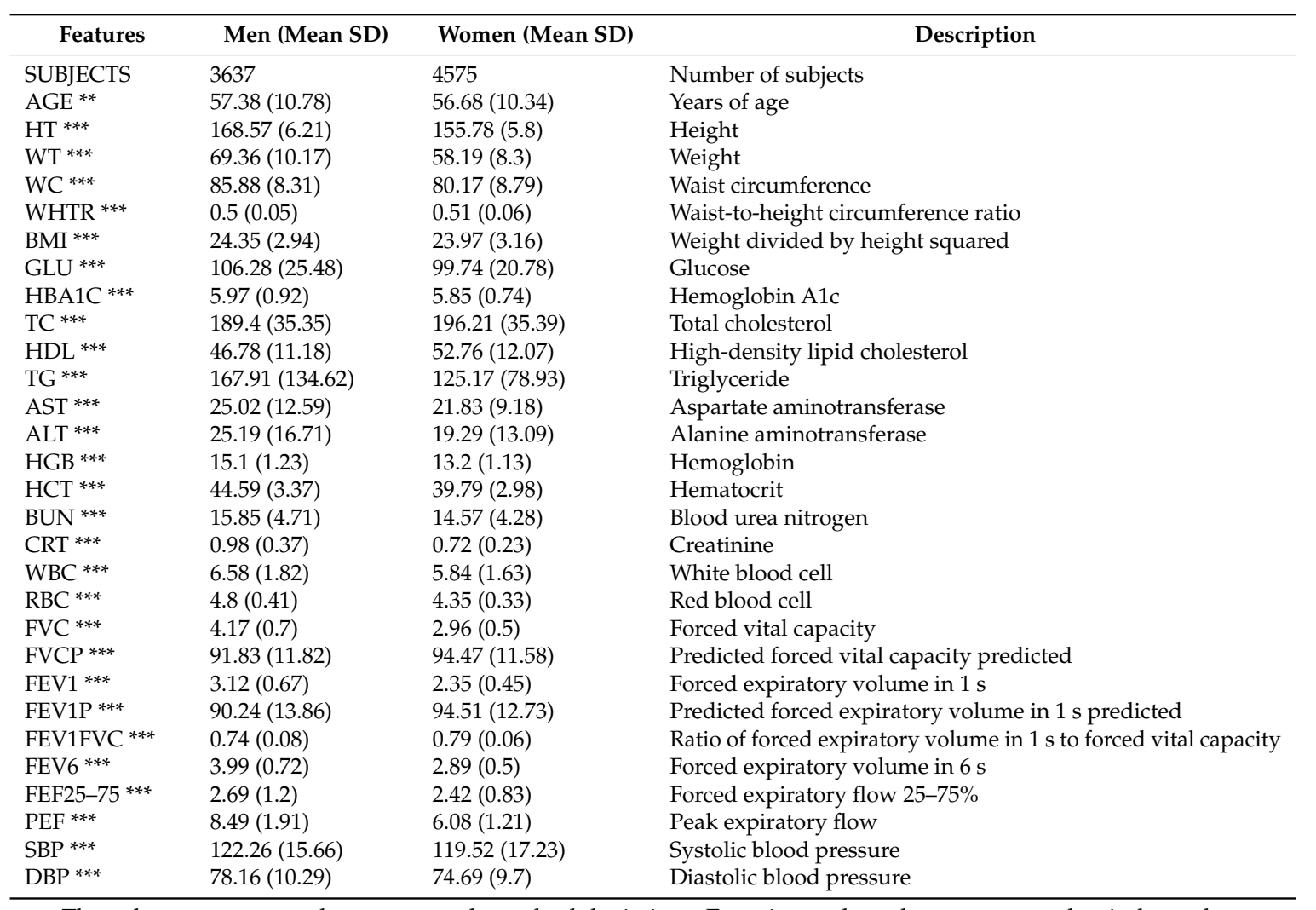

The values are expressed as means and standard deviations; Experimental results are presented as independent $t$-tests to verify statistical differences between two groups of men and women; and the statistical significance criteria are as follows: ${ }^{* *}: p<0.01,{ }^{* * *}: p<0.0001$.

\subsection{Performance Evaluation}

The prehypertension and hypertension predictive models were tested using the area under the receiver operating characteristic curve (AUC), and the performance of each predictive model was evaluated through analyses of sensitivity and (1-specificity). Sensitivity indicates that the response value was predicted to be positive in the positive case, and (1-specificity) is the false positive value in the negative case. The data were standardized such that the numerical data in different ranges could be analyzed on the same line. A ten-fold cross-validation test was performed to evaluate the predictive power of each model. 


\section{Results}

The normal BP group included 1068 (13\%) men and 1967 (24\%) women, whereas the prehypertension group included 983 (12\%) men and 1019 (12.4\%) women, and the hypertension group included 1586 (19.3\%) men and 1589 (19.3\%) women. In the statistical analyses, $p$-values, odds ratios (ORs), and 95\% confidence intervals (CIs) for each feature were obtained using binary LR. Tables 2 and 3 show the significance of differences in the studied variables between normotension and prehypertension or hypertension after adjustment for age in men and women.

Table 2. Results of statistical analyses of differences between normotension and prehypertension in men and women.

\begin{tabular}{ccccc}
\hline & Men & & Women & \\
\hline Features & $p$ & OR (95\% CI) & $p$ & OR (95\% CI) \\
\hline HT & 0.6494 & $0.978(0.890-1.074)$ & 0.1333 & $0.939(0.866-1.019)$ \\
WT & $<0.0001$ & $1.364(1.241-1.500)$ & $<0.0001$ & $1.348(1.248-1.455)$ \\
WC & $<0.0001$ & $1.318(1.206-1.441)$ & $<0.0001$ & $1.385(1.281-1.498)$ \\
WHTR & $<0.0001$ & $1.335(1.219-1.462)$ & $<0.0001$ & $1.424(1.313-1.545)$ \\
BMI & $<0.0001$ & $1.429(1.303-1.567)$ & $<0.0001$ & $1.427(1.321-1.542)$ \\
GLU & 0.0042 & $1.142(1.042-1.251)$ & $<0.0001$ & $1.289(1.180-1.410)$ \\
HBA1C & 0.1937 & $1.059(0.970-1.157)$ & $<0.0001$ & $1.225(1.126-1.333)$ \\
TC & 0.0102 & $1.122(1.027-1.225)$ & $<0.0001$ & $1.229(1.139-1.326)$ \\
HDL & 0.0035 & $1.138(1.043-1.242)$ & 0.0381 & $0.924(0.857-0.995)$ \\
TG & 0.0001 & $1.203(1.093-1.323)$ & $<0.0001$ & $1.259(1.162-1.365)$ \\
AST & 0.0006 & $1.193(1.078-1.320)$ & 0.0990 & $1.070(0.987-1.160)$ \\
ALT & 0.0004 & $1.187(1.078-1.308)$ & $<0.0001$ & $1.191(1.092-1.300)$ \\
HGB & $<0.0001$ & $1.322(1.204-1.452)$ & $<0.0001$ & $1.166(1.080-1.259)$ \\
HCT & $<0.0001$ & $1.262(1.151-1.383)$ & 0.0001 & $1.159(1.074-1.250)$ \\
BUN & 0.1314 & $0.933(0.854-1.020)$ & 0.1414 & $0.943(0.872-1.019)$ \\
CRT & 0.6373 & $0.979(0.898-1.068)$ & 0.8151 & $0.991(0.921-1.066)$ \\
WBC & 0.0673 & $1.084(0.994-1.183)$ & $<0.0001$ & $1.216(1.126-1.313)$ \\
RBC & 0.0009 & $1.168(1.065-1.281)$ & $<0.0001$ & $1.285(1.191-1.385)$ \\
FVC & 0.5738 & $1.029(0.931-1.137)$ & $<0.0001$ & $0.827(0.759-0.902)$ \\
FVCP & 0.8888 & $0.993(0.909-1.085)$ & $<0.0001$ & $0.814(0.755-0.877)$ \\
FEV1 & 0.6471 & $1.026(0.916-1.150)$ & 0.0004 & $0.846(0.770-0.928)$ \\
FEV1P & 0.3469 & $1.042(0.955-1.138)$ & 0.0016 & $0.886(0.822-0.955)$ \\
FEV1FVC & 0.8762 & $1.007(0.912-1.113)$ & 0.3055 & $1.042(0.962-1.129)$ \\
FEV6 & 0.7524 & $1.017(0.914-1.130)$ & $<0.0001$ & $0.817(0.747-0.893)$ \\
FEF25-75 & 0.9208 & $0.994(0.891-1.109)$ & 0.6338 & $1.021(0.937-1.112)$ \\
PEF & 0.9393 & $1.003(0.908-1.109)$ & 0.1210 & $0.937(0.864-1.017)$ \\
\hline
\end{tabular}

The results of binary logistic regression analyses adjusted by age ( $p$ value, OR and $95 \% \mathrm{CI}$ ) for each feature in men and women are shown. Abbreviations: $\mathrm{OR}$, odds ratio; $\mathrm{CI}$, confidential interval.

\subsection{Statistical Analysis of Prehypertension}

In men, BMI $(\mathrm{OR}=1.429,95 \% \mathrm{CI}=1.304-1.567)$ was identified as the best indicator of prehypertension. WT $(\mathrm{OR}=1.365,95 \% \mathrm{CI}=1.242-1.500)$ and $\mathrm{WHTR}(\mathrm{OR}=1.335,95 \% \mathrm{CI}=1.219-1.462)$ were also significantly associated with prehypertension. Among the blood parameters, hemoglobin (HGB; OR $=1.323,95 \%$ CI $=1.204-1.453$ ) exhibited an association with prehypertension in men. No spirometric indices were significant. In women, BMI (OR $=1.428,95 \% \mathrm{CI}=1.322-1.542)$ was found to be the best indicator, and WHTR $(\mathrm{OR}=1.425,95 \% \mathrm{CI}=1.313-1.546)$ and WC $(\mathrm{OR}=1.386$, $95 \% \mathrm{CI}=1.282-1.498)$ were also significantly associated with prehypertension. Among the blood parameters, glucose (GLU) $(\mathrm{OR}=1.290,95 \% \mathrm{CI}=1.180-1.410)$ was associated with prehypertension in women, and among the spirometric indices, the FVCP $(\mathrm{OR}=0.814,95 \% \mathrm{CI}=0.755-0.878)$ exhibited an association with prehypertension in women. 


\subsection{Statistical Analysis of Hypertension}

In men, $\mathrm{BMI}(\mathrm{OR}=1.993,95 \% \mathrm{CI}=1.818-2.186)$ was found to be the best indicator of hypertension, and WHTR $(\mathrm{OR}=1.903,95 \% \mathrm{CI}=1.735-2.087)$ and $\mathrm{WC}(\mathrm{OR}=1.790,95 \% \mathrm{CI}=1.638-1.956)$ were also significantly associated with hypertension. Among the blood parameters, TG $(\mathrm{OR}=1.434$, $95 \% \mathrm{CI}=1.304-1.577)$ exhibited a significant association with hypertension in men, and among the spirometric indices, FVCP $(\mathrm{OR}=0.791,95 \% \mathrm{CI}=0.728-0.859)$ showed a significant association with hypertension in men. In women, WHTR $(\mathrm{OR}=2.071,95 \% \mathrm{CI}=1.884-2.276)$ was identified as the best indicator of hypertension, and BMI $(\mathrm{OR}=2.034,95 \% \mathrm{CI}=1.861-2.222)$ and WC $(\mathrm{OR}=1.927$, $95 \% \mathrm{CI}=1.764-2.105)$ were also significantly associated with hypertension. Among the blood parameters, GLU (OR $=1.676,95 \% \mathrm{CI}=1.508-1.861)$ exhibited a significant association with hypertension in women. Among the spirometric indices, the FVCP $(\mathrm{OR}=0.682,95 \% \mathrm{CI}=0.629-0.739)$ was found to be significantly associated with hypertension in women.

Table 3. Results of statistical analyses of differences between normotension and hypertension in men and women.

\begin{tabular}{ccccc}
\hline & Men & & Women & \\
\hline Features & $p$ & OR (95\% CI) & $p$ & OR (95\% CI) \\
\hline HT & 0.0139 & $0.896(0.822-0.978)$ & 0.0048 & $0.883(0.810-0.963)$ \\
WT & $<0.0001$ & $1.745(1.592-1.912)$ & $<0.0001$ & $1.768(1.627-1.921)$ \\
WC & $<0.0001$ & $1.789(1.637-1.955)$ & $<0.0001$ & $1.927(1.764-2.105)$ \\
WHTR & $<0.0001$ & $1.902(1.734-2.086)$ & $<0.0001$ & $2.071(1.884-2.276)$ \\
BMI & $<0.0001$ & $1.993(1.817-2.185)$ & $<0.0001$ & $2.033(1.861-2.221)$ \\
GLU & $<0.0001$ & $1.363(1.247-1.489)$ & $<0.0001$ & $1.675(1.508-1.861)$ \\
HBA1C & $<0.0001$ & $1.248(1.148-1.357)$ & $<0.0001$ & $1.539(1.393-1.700)$ \\
TC & 0.0085 & $0.897(0.827-0.972)$ & 0.6831 & $0.984(0.912-1.061)$ \\
HDL & 0.5808 & $1.022(0.944-1.106)$ & 0.0001 & $0.857(0.792-0.926)$ \\
TG & $<0.0001$ & $1.434(1.304-1.576)$ & $<0.0001$ & $1.423(1.306-1.551)$ \\
AST & $<0.0001$ & $1.341(1.212-1.485)$ & $<0.0001$ & $1.238(1.134-1.350)$ \\
ALT & $<0.0001$ & $1.310(1.198-1.432)$ & $<0.0001$ & $1.453(1.317-1.602)$ \\
HGB & 0.0001 & $1.175(1.081-1.278)$ & $<0.0001$ & $1.251(1.151-1.359)$ \\
HCT & 0.0055 & $1.123(1.034-1.220)$ & $<0.0001$ & $1.205(1.112-1.306)$ \\
BUN & 0.4573 & $1.030(0.951-1.117)$ & 0.0836 & $1.076(0.990-1.169)$ \\
CRT & 0.0110 & $1.235(1.049-1.453)$ & 0.0001 & $1.334(1.149-1.549)$ \\
WBC & $<0.0001$ & $1.183(1.092-1.282)$ & $<0.0001$ & $1.347(1.243-1.460)$ \\
RBC & 0.0006 & $1.158(1.064-1.260)$ & $<0.0001$ & $1.390(1.283-1.505)$ \\
FVC & $<0.0001$ & $0.817(0.744-0.898)$ & $<0.0001$ & $0.694(0.630-0.764)$ \\
FVCP & $<0.0001$ & $0.791(0.728-0.859)$ & $<0.0001$ & $0.681(0.629-0.739)$ \\
FEV1 & 0.0263 & $0.888(0.799-0.986)$ & $<0.0001$ & $0.753(0.679-0.835)$ \\
FEV1P & 0.3479 & $0.962(0.888-1.042)$ & $<0.0001$ & $0.827(0.763-0.895)$ \\
FEV1FVC & 0.0046 & $1.138(1.040-1.245)$ & 0.0002 & $1.170(1.076-1.272)$ \\
FEV6 & $<0.0001$ & $0.806(0.729-0.890)$ & $<0.0001$ & $0.682(0.617-0.754)$ \\
FEF25-75 & 0.2276 & $1.063(0.962-1.176)$ & 0.2248 & $1.057(0.966-1.157)$ \\
PEF & 0.1416 & $0.933(0.852-1.023)$ & 0.5117 & $0.970(0.888-1.060)$ \\
\hline
\end{tabular}

The results of the binary logistic regression analysis adjusted by age ( $p$ value, OR and $95 \% \mathrm{CI}$ ) for each feature in men and women are shown. Abbreviations: OR, odds ratio; CI, confidential interval.

\subsection{Performance Evaluation of the Prehypertension Prediction Model Combined with Feature Selection}

We developed prediction models for prehypertension and hypertension using feature selection methods and classification algorithms. Features were selected using the CFS and WFS methods, and the predictive models were developed by applying the LR, NB, and DT algorithms with the selected features. The AUC was used to evaluate the performance of each prediction model.

The analysis of the prehypertension prediction model revealed that the WFS-LR model with AGE, BMI, GLU, TC, HDL-C, TG, aspartate aminotransferase (AST), HGB and blood urea nitrogen (BUN) showed the best predictive power (AUC $=0.635$ ) for men, with a sensitivity of 0.52 and a1-specificity of 
0.338. In contrast, the CFS-DT model showed the lowest predictive power (AUC $=0.559$ ). For women, the WFS-LR model with AGE, WHTR, BMI, GLU, TC, TG, WBC, RBC and FVCP and peak expiratory flow $(\mathrm{PEF})$ showed the best predictive power $(\mathrm{AUC}=0.700)$, with a sensitivity of 0.308 and a 1 -specificity of 0.11 , whereas the CFS-DT model exhibited the lowest predictive power (AUC $=0.622$ ).

The predictive performance of the prehypertension prediction model is compared and shown in Figure 2. The analyses of the prehypertension prediction model for men showed that the AUCs of LR, NB, and DT based on CFS were 0.610, 0.602 and 0.559, respectively, and that the AUCs of LR, $\mathrm{NB}$, and DT based on WFS were $0.635,0.626$, and 0.580 , respectively. In contrast, the AUCs of the prehypertension prediction model for women generated using LR, NB, and DT based on CFS were 0.698, 0.691 and 0.622, respectively, and the AUCs of LR, NB, and DT based on WFS were 0.700, 0.699 and 0.646 , respectively.

\subsection{Performance Evaluation of the Hypertension Prediction Models Combined with Feature Selection}

Analyses of the hypertension prediction models revealed that the WFS-LR model with WHTR, BMI, GLU, TC, HDL-C, TG, AST, BUN, creatinine (CRT), WBC, FVC, the FEV1 to FVC ratio (FEV1FVC), FEV in $6 \mathrm{~s}$ (FEV6) and PEF showed the best predictive power (AUC $=0.777)$ for men. The sensitivity and 1-specificity of this model were 0.813 and 0.401 , respectively. The CFS-DT model showed the lowest predictability (AUC $=0.666$ ). For women, the WFS-LR model with AGE, WC, BMI, GLU, TC, HDL-C, TG, alanine aminotransferase (ALT), CRT, WBC, RBC, FVC, FEV6 and forced expiratory flow $25-75 \%$ (FEF 25-75) showed the best predictive power (AUC $=0.845$ ), with a sensitivity of 0.724 and a 1 -specificity of 0.191 , and the CFS-DT model exhibited the lowest predictive power (AUC $=0.796$ ).

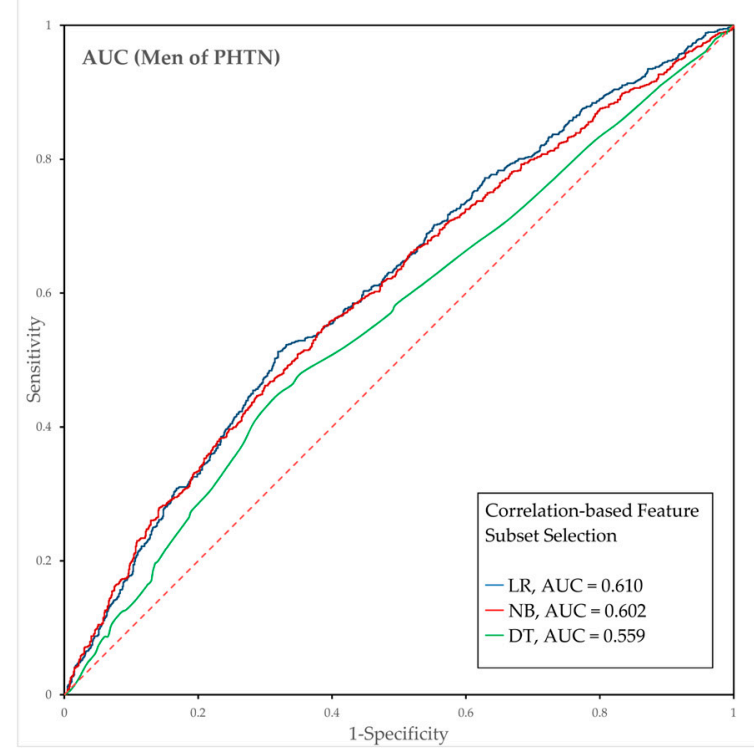

(a)

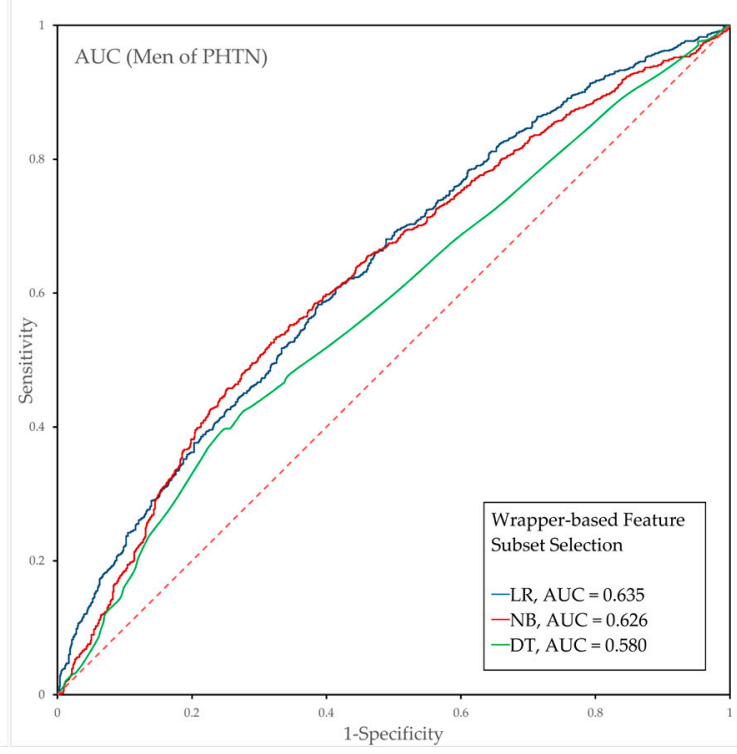

(b)

Figure 2. Cont. 


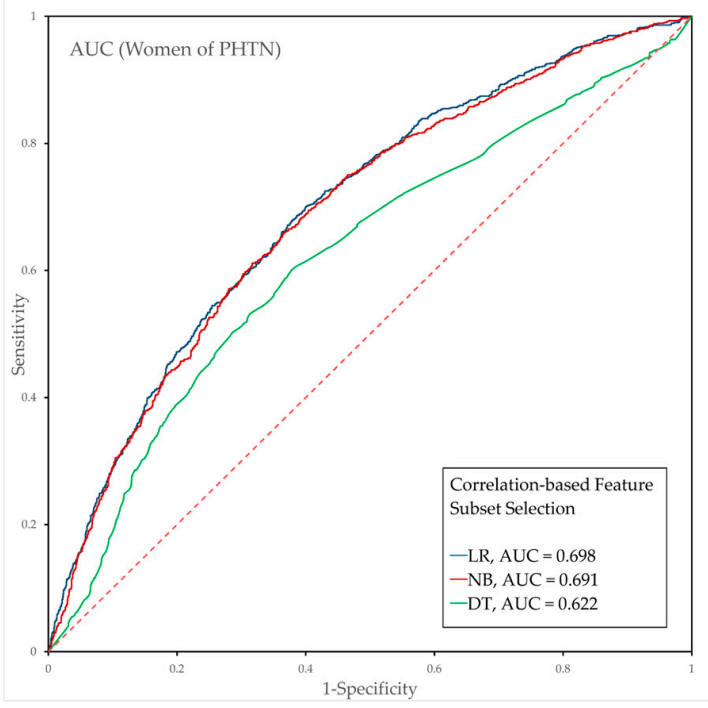

(c)

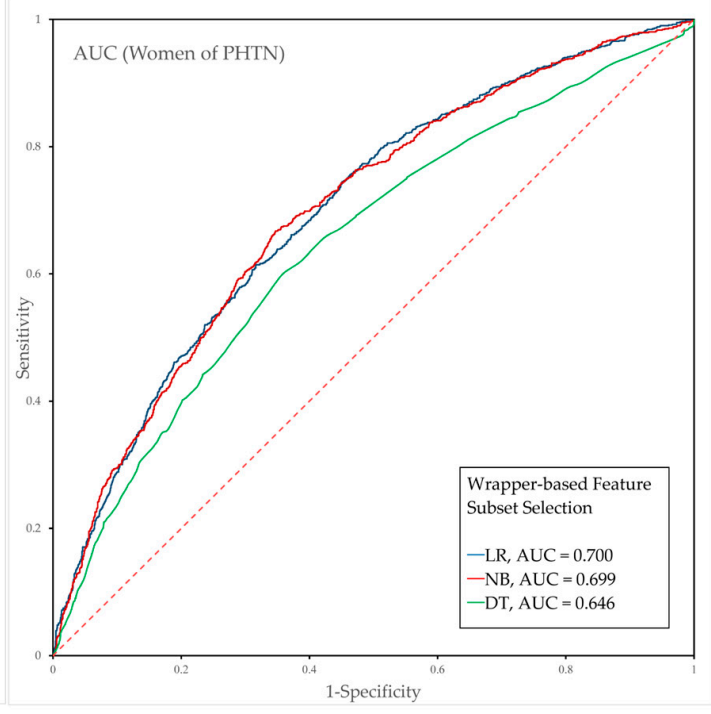

(d)

Figure 2. Predictive power of each prehypertension prediction model for men and women. Each graph presents the results for the LR, NB, and DT algorithms. (a,b) present the results for men, and (c,d) present the results for women. $(\mathbf{a}, \mathbf{c})$ show the results obtained with CFS, and $(\mathbf{b}, \mathbf{d})$ show the results obtained with WFS. Abbreviations: LR, logistic regression; NB, naïve Bayes; DT, decision tree; AUC, area under the receiver operating characteristic curve; PHTN, prehypertension; CFS, correlation-based Feature selection; WFS, wrapper-based feature selection.

Table 4. Details of the prediction models of prehypertension and hypertension.

\begin{tabular}{|c|c|c|c|}
\hline Sex & BPS & FSM & Selected Features \\
\hline \multirow{4}{*}{ Men } & \multirow[b]{2}{*}{ PHTN } & CFS & WT, WHTR, BMI, GLU, AST, ALT, HGB \\
\hline & & WFS & $\begin{array}{l}\text { LR: AGE, BMI, GLU, TC, HDL, TG, AST, HGB and BUN; } \\
\text { NB: AGE, BMI, GLU, HDL, TG, AST and WBC; } \\
\text { DT: HT, BMI, GLU, TG, WBC and FEV1; }\end{array}$ \\
\hline & \multirow[b]{2}{*}{ HTN } & CFS & AGE, WC, WHTR, BMI, GLU, HBA1C, AST, CRT, FVC and FEV1 \\
\hline & & WFS & $\begin{array}{l}\text { LR: AGE, WHTR, BMI, GLU, TC, HDL, TG, AST, BUN, CRT, } \\
\text { WBC, FVC, FEV1FVC, FEV6 and PEF; } \\
\text { NB: AGE, WHTR, BMI, GLU, TC, HDL, AST, HGB and PEF; } \\
\text { DT: AGE, WHTR, BMI, AST and FEV6; }\end{array}$ \\
\hline \multirow{4}{*}{ Women } & \multirow[b]{2}{*}{ PHTN } & CFS & $\begin{array}{l}\text { AGE, WT, WC, WHTR, BMI, GLU, HBA1C, TC, TG, HGB, RBC, } \\
\text { FVC, FEV1, FEV6 and PEF }\end{array}$ \\
\hline & & WFS & $\begin{array}{l}\text { LR: AGE, WHTR, BMI, GLU, TC, TG, WBC, RBC and FVCP; } \\
\text { NB: AGE, WT, WHTR, TC, TG, HGB, RBC, FVCP and PEF; } \\
\text { DT: AGE, WHTR, BMI, GLU, HCT, RBC, FEV1 and FEV1P; }\end{array}$ \\
\hline & \multirow[b]{2}{*}{ HTN } & CFS & $\begin{array}{l}\text { AGE, WC, WHTR, BMI, GLU, HBA1C, TG, ALT, CRT, RBC, FEV1, } \\
\text { FEV6 and PEF }\end{array}$ \\
\hline & & WFS & $\begin{array}{l}\text { LR: AGE, WC, BMI, GLU, TC, HDL, TG, ALT, CRT, WBC, RBC, } \\
\text { FVC, FEV6 and FEF25-75; } \\
\text { NB: AGE, BMI, TC, HGB, RBC and FVCP; } \\
\text { DT: AGE, BMI, GLU and HGB; }\end{array}$ \\
\hline
\end{tabular}

Abbreviations: FSM, feature selection method; BP, blood pressure status; PHTN, prehypertension; HTN, hypertension; CFS, correlation-based feature selection; WFS, wrapper-based feature selection; LR, logistic regression; $\mathrm{NB}$, naïve Bayes; DT, decision tree; AUC, area under the receiver operating characteristic curve.

The predictive performance of the hypertension prediction model is compared and shown in Figure 3. The analysis of the hypertension prediction model for men showed that the AUCs of LR, NB, 
and DT based on CFS were $0.749,0.732$ and 0.666 , respectively, and that the AUCs of LR, NB, and DT based on WFS were $0.777,0.748$ and 0.698 , respectively. In contrast, the AUCs of the hypertension prediction model for women generated through LR, NB, and DT based on CFS were $0.843,0.819$ and 0.761 , respectively, and the AUCs of LR, NB, and DT based on WFS were $0.845,0.833$ and 0.796 , respectively.

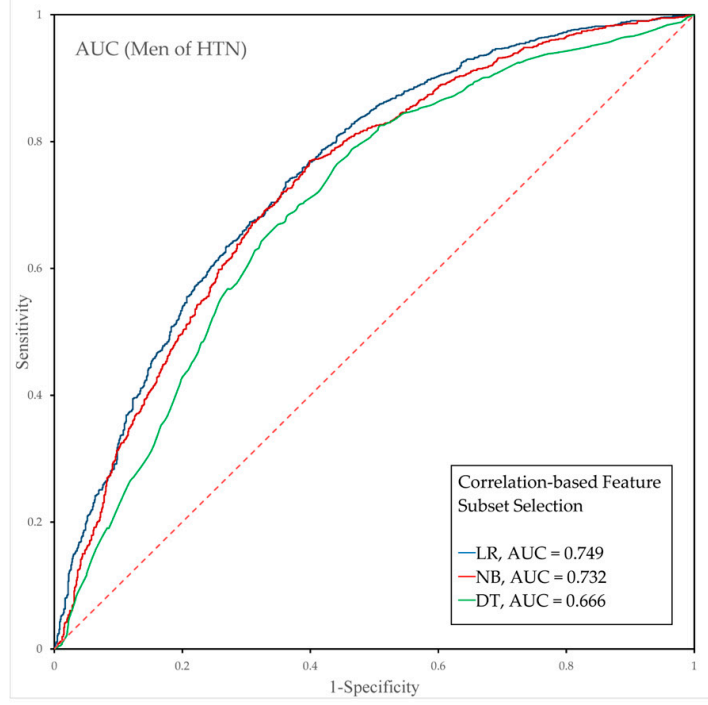

(a)

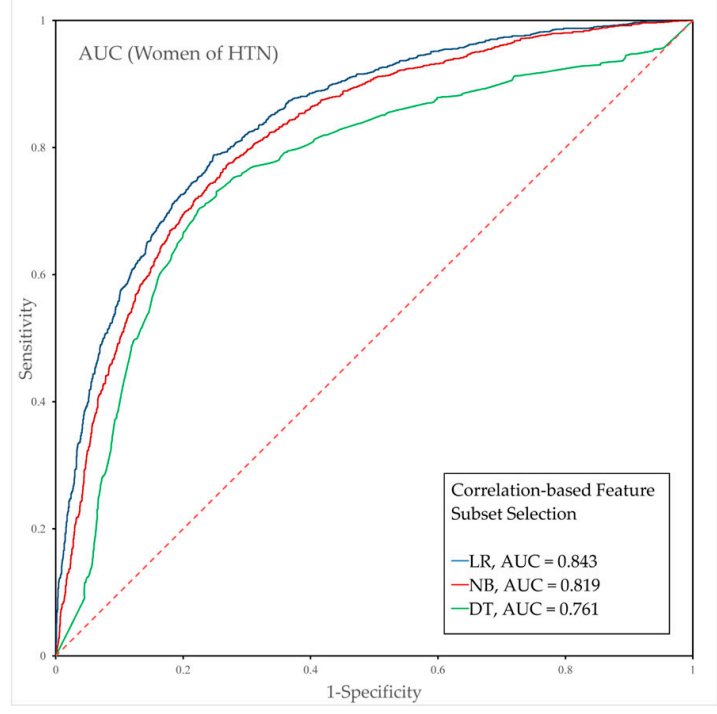

(c)

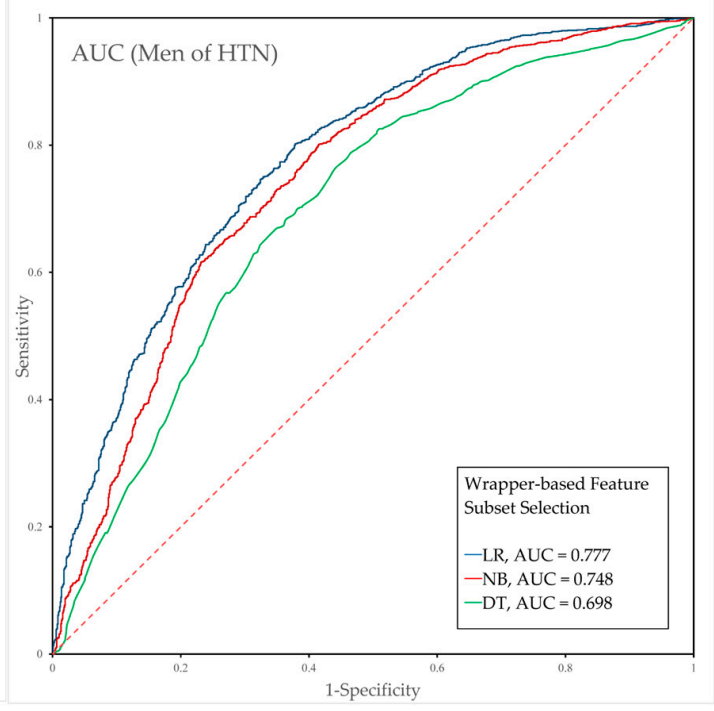

(b)

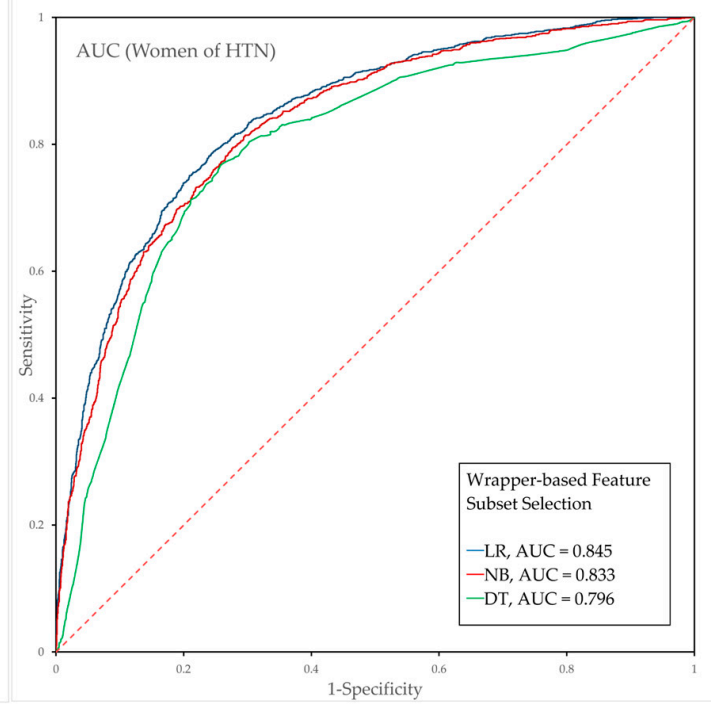

(d)

Figure 3. Predictive power of each hypertension prediction model for men and women. Each graph presents the results for the LR, NB, and DT algorithms. (a,b) present the results for men, and (c,d) present the results for women. $(\mathbf{a}, \mathbf{c})$ show the results obtained with CFS, and $(\mathbf{b}, \mathbf{d})$ show the results obtained with WFS. Abbreviations: LR, logistic regression; NB, naïve Bayes; DT, decision tree; AUC, area under the receiver operating characteristic curve; HTN, hypertension; CFS, correlation-based feature selection; WFS, wrapper-based feature selection.

The features and performance results of the prehypertension and hypertension prediction models are summarized in Table 4 . In men, the WFS-LR showed satisfactory performance (AUC $=0.635$ ) in the prehypertension prediction model and the best performance (AUC $=0.777$ ) in the hypertension prediction model. In contrast, in women, the WFS-LR showed satisfactory performance (AUC $=0.700$ ) in the prehypertension prediction model and the best performance ( $\mathrm{AUC}=0.845$ ) in the hypertension 
prediction model. Among the classification methods, LR exhibited higher prediction performance than did NB and DT. The hypertension prediction model performed better than the prehypertension prediction model and showed better performance in women than in men.

\section{Discussion}

In this study, anthropometric indices, blood parameters, and spirometric indices were examined to identify risk factors for prehypertension and hypertension. The features for the prehypertension and hypertension prediction models were selected using the CFS and WFS methods. Prediction models were then developed using the LR, NB, and DT classification algorithms.

In a previous study, Ko and colleagues analyzed the associations of BMI, WHR, WC, and WHTR with hypertension in a Chinese population in Hong Kong and found that WHTR was the strongest indicator in men $(\mathrm{OR}=1.18,95 \% \mathrm{CI}=1.14-1.23)$ whereas WHR was the strongest indicator in women $(\mathrm{OR}=1.26,95 \% \mathrm{CI}=1.18-1.35)$ [30]. Lee and colleagues demonstrated that among obesity factors, WC, WHR, and WHTR, were more predictive of hypertension than was BMI and that WHTR was the best obesity-related predictor of hypertension, regardless of gender, ethnicity and age [hazard ratio $(\mathrm{HR})=1.49,95 \% \mathrm{CI}=1.35-1.65$ in men and $\mathrm{HR}=1.48,95 \% \mathrm{CI}=1.33-1.64$ in women] in middle-aged Korean adults [32]. Chang and colleagues found that BMI in men (OR $=2.07,95 \% \mathrm{CI}=1.44-2.99)$ and abdominal obesity in women $(\mathrm{OR}=2.04,95 \% \mathrm{CI}=1.54-2.71)$ were associated with an increased risk of prehypertension [45]. Grievink and colleagues evaluated BMI, WC, and WHR as predictors of hypertension in a Caribbean population and identified WC $(\mathrm{OR}=1.7,95 \% \mathrm{CI}=1.4-2.0)$ as the best independent predictor of hypertension [24]. Tsai and colleagues reported that WHR, BMI, and WC were associated with prehypertension, particularly high $\mathrm{BMI}$ in men $(\mathrm{OR}=1.106,95 \% \mathrm{CI}=1.051)$ and high WC in women $(\mathrm{OR}=1.031,95 \% \mathrm{CI}=1.012-1.051)$ [33]. In this study, BMI was identified as the best predictor of prehypertension in men $(\mathrm{OR}=1.429,95 \% \mathrm{CI}=1.303-1.567)$ and women $(\mathrm{OR}=1.427,95 \%$ $\mathrm{CI}=1.321-1.542)$. The risk factors that best predicted hypertension were $\mathrm{BMI}$ in men $(\mathrm{OR}=1.993,95 \%$ $\mathrm{CI}=1.817-2.185)$ and WHTR in women $(\mathrm{OR}=2.071,95 \% \mathrm{CI}=1.884-2.276)$. Our findings are consistent with those of previous studies [27-29] and indicate that BMI is the best indicator of hypertension in men and of prehypertension in men and women.

Several studies of blood parameters and hypertension have been conducted. Cirillo and colleagues reported that hematocrit level was positively correlated with SBP and DBP in men and women [34]. In addition, Emamian and colleagues performed a multivariate LR analysis of demographic, biochemical, and hematological parameters and found that hematocrit $(\mathrm{OR}=1.02,95 \% \mathrm{CI}=1.003-1.04)$ was an independent predictor of hypertension [35]. Daniel and colleagues demonstrated that high HbA1c levels were associated with increased hypertension rate and that the rate of $\mathrm{CVD}(\mathrm{OR}=1.39,95 \% \mathrm{CI}=1.06-1.83)$ increased by $1 \%$ with each increase in $\mathrm{HbA1c}$ level [36]. Christina and colleagues showed that men and women with prehypertension presented $31 \%$ higher CRP, 32\% higher tumor necrosis factor-a, $9 \%$ higher amyloid-a, $6 \%$ higher homocysteine, and 10\% higher WBC levels [38]. In this study, the best predictor of prehypertension was found to be HBG (OR $=1.322,95 \% \mathrm{CI}=1.204-1.452)$ in men and GLU $(\mathrm{OR}=1.289,95 \% \mathrm{CI}=1.180-1.410)$ in women. $\mathrm{HCT}(\mathrm{OR}=1.262,95 \% \mathrm{CI}=1.151-1.383)$ and $\mathrm{TG}(\mathrm{OR}=1.259,95 \% \mathrm{CI}=1.162-1.365)$ were also highly associated with prehypertension in men and women, respectively. The best predictor of hypertension was TG $(\mathrm{OR}=1.434,95 \% \mathrm{CI}=1.304-1.576)$ in men and GLU $(\mathrm{OR}=1.675,95 \% \mathrm{CI}=1.508-1.861)$ in women. $\mathrm{GLU}(\mathrm{OR}=1.363,95 \% \mathrm{CI}=1.247-1.489)$ and $\mathrm{HbA} 1 \mathrm{c}(\mathrm{OR}=1.539,95 \% \mathrm{CI}=1.393-1.700)$ were also highly associated with hypertension in men and women, respectively. Our findings are consistent with those of previous studies [36] and indicate that the $\mathrm{HbA} 1 \mathrm{c}$ index is significantly associated with hypertension in women.

Through a study of hypertension and spirometry, Sarah and colleagues demonstrated that FVC was significantly associated with hypertension and a negative predictor [39]. Follow-up studies showed that hypertension could develop in the future, and an OR of approximately 0.7 was found in an LR analysis [39]. Jacobs and colleagues performed an HR analysis and found that the risk of hypertension (HR from 1 to 2.21) increased by more than 2 -fold with decreasing FVC and that a low 
FVC might result in cardiovascular morbidity and mortality [40]. In this study, FVCP was identified as the best predictor of prehypertension and hypertension. Low FVCP indices were associated with prehypertension in women $(\mathrm{OR}=0.814,95 \% \mathrm{CI}=0.755-0.877)$, hypertension in men $(\mathrm{OR}=0.791,95 \%$ $\mathrm{CI}=0.728-0.859)$ and hypertension in women $(\mathrm{OR}=0.681,95 \% \mathrm{CI}=0.629-0.739)$. FVC predictors were also significantly associated with hypertension, but the associations were slightly less significant than the association of FVCP with hypertension. Our findings are consistent with those of previous studies $[39,40]$ and indicate that the FVC index is significantly associated with prehypertension in women and hypertension in men and women.

Prior to the present study, several researchers have proposed hypertension prediction model based on data mining techniques [50-53]. For instance, Tayefi and colleagues proposed a hypertension prediction model based on DTs in the Iranian population. The hypertension DT model suggested that demographics and selected biochemical markers (such as age, BMI, fasting blood GLU, TG, UA, hs-CRP, TC and LDL-C) have higher predictive power than other biochemical markers [50]. Ture and colleagues compared the performance of DTs, statistical algorithms, and neural networks using features such as age, sex, family history, smoking habits, lipoprotein, TG and UA and found that the neural network algorithm had the best predictive power for hypertension [51]. The evaluation of the performance of DT, NB, and LR performed in this study identified LR as the best classification algorithm. The model combining the demographic index, blood parameters and spirometric indices showed the best predictive power. Among the prediction models of prehypertension and hypertension, the WFS-LR prediction models were identified as the best for both men and women. A hypertension prediction model was then developed by combining the obesity index, blood parameters, and spirometric indices, whereas previous studies $[50,51]$ used demographic characteristics, BMI, and blood parameters.

This study has several limitations. First, it is difficult to identify cause-and-effect relationships because we used data from a cross-sectional survey. Second, the most significant risk factor for hypertension was the obesity index, but hip circumference was not measured and could not be compared to WHR. Third, we did not have information on disease (diabetes, dyslipidemia, and hyperlipidemia) secondary to hypertension, so we did not consider it in this study. Finally, in this study, the predictive model was designed considering only anthropometric indices, blood parameters, and spirometric indices, and indicators such as smoking, drinking, and physical activity were excluded.

\section{Conclusions}

Hypertension is a risk factor that can lead to cardiovascular diseases and death, and treatment and management strategies for hypertension remain lacking. In this study, we examined the associations of prehypertension and hypertension with spirometric indices, obesity indices, and blood parameters and proposed prehypertension and hypertension prediction models to aid the effective management and prevention of hypertension. A statistical analysis of the three types of variables revealed that the obesity indices were the highest risk factors for prehypertension and hypertension in men and women. GLU, HbA1c, and TG as well as low spirometric values were also associated with hypertension in both men and women. Thus, we developed prediction models with the LR, NB and DT classifiers using two subset selection methods, namely, CFS and WFS. The predictive model with the highest prediction power was the WFS-LR prediction model that combined various factors (i.e., age, obesity indices, blood parameters, and spirometric indices). Our findings can be applied as a large-scale screening tool for the control and management of hypertension.

Author Contributions: B.M.H. conceived the analyses and developed the study concepts. B.M.H. and K.H.R. made substantial contributions to the statistical analyses and data interpretation. B.M.H. wrote the first draft of this manuscript, and B.M.H. and K.H.R. revised the article. All the authors approved the final version submitted for publication.

Funding: This research was supported by the Basic Science Research Program through the National Research Foundation of Korea (NRF) funded by the Ministry of Science, ICT \& Future Planning (No. 2017R1A2B4010826). 
Acknowledgments: We would like to thank the Korea Centers for Disease Control and Prevention who provided data for this study and colleagues who helped with the research consultation.

Conflicts of Interest: The authors have no conflict of interest or financial disclosures.

\section{References}

1. James, P.A.; Oparil, S.; Carter, B.L.; Cushman, W.C.; Dennison-Himmelfarb, C.; Handler, J.; Lackland, D.T.; LeFevre, M.L.; MacKenzie, T.D.; Ogedegbe, O. 2014 evidence-based guideline for the management of high blood pressure in adults: Report from the panel members appointed to the Eighth Joint National Committee (JNC 8). Jama 2014, 311, 507-520. [CrossRef] [PubMed]

2. Lawes, C.M.; Vander Hoorn, S.; Rodgers, A. Global burden of blood-pressure-related disease, 2001. Lancet 2008, 371, 1513-1518. [CrossRef]

3. Ogden, L.G.; He, J.; Lydick, E.; Whelton, P.K. Long-term absolute benefit of lowering blood pressure in hypertensive patients according to the JNC VI risk stratification. Hypertension 2000, 35, 539-543. [CrossRef] [PubMed]

4. Kannel, W.B. Blood pressure as a cardiovascular risk factor: Prevention and treatment. Jama 1996, 275, 1571-1576. [CrossRef] [PubMed]

5. World Health Organization; International Society of Hypertension Writing Group. 2003 World Health Organization (WHO)/International Society of Hypertension (ISH) statement on management of hypertension. J. Hypertens. 2003, 21, 1983-1992. [CrossRef]

6. Muntner, P.; Anderson, A.; Charleston, J.; Chen, Z.; Ford, V.; Makos, G.; O'Connor, A.; Perumal, K.; Rahman, M.; Steigerwalt, S. Hypertension awareness, treatment, and control in adults with CKD: Results from the Chronic Renal Insufficiency Cohort (CRIC) Study. Am. J. Kidney Dis. 2010, 55, 441-451. [CrossRef] [PubMed]

7. Whelton, P.K.; Carey, R.M.; Aronow, W.S.; Casey, D.E.; Collins, K.J.; Himmelfarb, C.D.; DePalma, S.M.; Gidding, S.; Jamerson, K.A.; Jones, D.W. 2017 ACC/AHA/AAPA/ABC/ACPM/AGS/APhA/ASH/ASPC/ NMA/PCNA Guideline for the Prevention, Detection, Evaluation, and Management of High Blood Pressure in Adults: A Report of the American College of Cardiology/American Heart Association Task Force on Clinical Practice Guidelines. J. Am. Coll. Cardiol. 2017, 71, e13-e115.

8. Gupta, A.K.; McGlone, M.; Greenway, F.L.; Johnson, W.D. Prehypertension in disease-free adults: A marker for an adverse cardiometabolic risk profile. Hypertens. Res. 2010, 33, 905-910. [CrossRef] [PubMed]

9. Vasan, R.S.; Larson, M.G.; Leip, E.P.; Evans, J.C.; O’Donnell, C.J.; Kannel, W.B.; Levy, D. Impact of high-normal blood pressure on the risk of cardiovascular disease. N. Engl. J. Med. 2001, 345, 1291-1297. [CrossRef] [PubMed]

10. Kim, M.-J.; Lim, N.-K.; Park, H.-Y. Relationship between prehypertension and chronic kidney disease in middle-aged people in Korea: The Korean genome and epidemiology study. BMC Public Health 2012, $12,960$. [CrossRef] [PubMed]

11. Greenlund, K.J.; Croft, J.B.; Mensah, G.A. Prevalence of heart disease and stroke risk factors in persons with prehypertension in the United States, 1999-2000. Arch. Intern. Med. 2004, 164, 2113-2118. [CrossRef]

12. Chan, Q.; Stamler, J.; Griep, L.M.O.; Daviglus, M.L.; Van Horn, L.; Elliott, P. An update on nutrients and blood pressure. J. Atheroscler. Thromb. 2016, 23, 276-289. [CrossRef] [PubMed]

13. Beckett, N.S.; Peters, R.; Fletcher, A.E.; Staessen, J.A.; Liu, L.; Dumitrascu, D.; Stoyanovsky, V.; Antikainen, R.L.; Nikitin, Y.; Anderson, C. Treatment of hypertension in patients 80 years of age or older. N. Engl. J. Med. 2008, 358, 1887-1898. [CrossRef] [PubMed]

14. Hansson, L.; Zanchetti, A.; Carruthers, S.G.; Dahlöf, B.; Elmfeldt, D.; Julius, S.; Ménard, J.; Rahn, K.H.; Wedel, H.; Westerling, S. Effects of intensive blood-pressure lowering and low-dose aspirin in patients with hypertension: Principal results of the Hypertension Optimal Treatment (HOT) randomised trial. Lancet 1998, 351, 1755-1762. [CrossRef]

15. Staessen, J.A.; Wang, J.-G.; Thijs, L. Cardiovascular protection and blood pressure reduction: A meta-analysis. Lancet 2001, 358, 1305-1315. [CrossRef]

16. Carr, M.J.; Bao, Y.; Pan, J.; Cruickshank, K.; McNamee, R. The predictive ability of blood pressure in elderly trial patients. J. Hypertens. 2012, 30, 1725-1733. [CrossRef] [PubMed] 
17. Kannel, W.B.; Vasan, R.S. Assessment of cardiovascular risk and choice of antihypertensive therapy. Curr. Hypertens. Rep. 2004, 6, 346-351. [CrossRef] [PubMed]

18. Tsai, J.-C.; Chang, W.-Y.; Kao, C.-C.; Lu, M.-S.; Chen, Y.-J.; Chan, P. Beneficial effect on blood pressure and lipid profile by programmed exercise training in Taiwanese patients with mild hypertension. Clin. Exp. Hypertens. 2002, 24, 315-324. [CrossRef] [PubMed]

19. Pescatello, L.S.; Franklin, B.A.; Fagard, R.; Farquhar, W.B.; Kelley, G.A.; Ray, C.A. Exercise and hypertension. Med. Sci. Sports Exerc. 2004, 36, 533-553. [CrossRef] [PubMed]

20. Liu, J.; Sui, X.; Lavie, C.J.; Zhou, H.; Park, Y.-M.M.; Cai, B.; Liu, J.; Blair, S.N. Effects of cardiorespiratory fitness on blood pressure trajectory with aging in a cohort of healthy men. J. Am. Coll. Cardiol. 2014, 64, 1245-1253. [CrossRef]

21. Carnethon, M.R.; Gidding, S.S.; Nehgme, R.; Sidney, S.; Jacobs, D.R., Jr.; Liu, K. Cardiorespiratory fitness in young adulthood and the development of cardiovascular disease risk factors. Jama 2003, 290, 3092-3100. [CrossRef] [PubMed]

22. Hayashi, T.; Tsumura, K.; Suematsu, C.; Okada, K.; Fujii, S.; Endo, G. Walking to work and the risk for hypertension in men: The Osaka Health Survey. Ann. Intern. Med. 1999, 131, 21-26. [CrossRef] [PubMed]

23. Okosun, I.S.; Cooper, R.S.; Rotimi, C.N.; Osotimehin, B.; Forrester, T. Association of waist circumference with risk of hypertension and type 2 diabetes in Nigerians, Jamaicans, and African-Americans. Diabetes Care 1998, 21, 1836-1842. [CrossRef] [PubMed]

24. Grievink, L.; Alberts, J.; O'niel, J.; Gerstenbluth, I. Waist circumference as a measurement of obesity in the Netherlands Antilles; associations with hypertension and diabetes mellitus. Eur. J. Clin. Nutr. 2004, 58, 1159-1165. [CrossRef] [PubMed]

25. Olinto, M.; Nacul, L.; Gigante, D.; Costa, J.; Menezes, A.; Macedo, S. Waist circumference as a determinant of hypertension and diabetes in Brazilian women: A population-based study. Public Health Nutr. 2004, 7, 629-635. [CrossRef] [PubMed]

26. Carba, D.B.; Bas, I.N.; Gultiano, S.A.; Lee, N.R.; Adair, L.S. Waist circumference and the risk of hypertension and prediabetes among Filipino women. Eur. J. Nutr. 2013, 52, 825-832. [CrossRef] [PubMed]

27. Dua, S.; Bhuker, M.; Sharma, P.; Dhall, M.; Kapoor, S. Body Mass Index Relates to Blood Pressure among Adults. N. Am. J. Med. Sci. 2014, 6, 89-95. [CrossRef] [PubMed]

28. Colin Bell, A.; Adair, L.S.; Popkin, B.M. Ethnic Differences in the Association between Body Mass Index and Hypertension. Am. J. Epidemiol. 2002, 155, 346-353. [CrossRef] [PubMed]

29. Dalton, M.; Cameron, A.; Zimmet, P.; Shaw, J.; Jolley, D.; Dunstan, D.; Welborn, T. Waist circumference, waist-hip ratio and body mass index and their correlation with cardiovascular disease risk factors in Australian adults. J. Intern. Med. 2003, 254, 555-563. [CrossRef] [PubMed]

30. Ko, G.T.; Chan, J.C.; Cockram, C.S.; Woo, J. Prediction of hypertension, diabetes, dyslipidaemia or albuminuria using simple anthropometric indexes in Hong Kong Chinese. Int. J. Obes. Relat. Metab. Disord. 1999, 23, 1136. [CrossRef] [PubMed]

31. Li, W.-C.; Chen, I.-C.; Chang, Y.-C.; Loke, S.-S.; Wang, S.-H.; Hsiao, K.-Y. Waist-to-height ratio, waist circumference, and body mass index as indices of cardiometabolic risk among 36,642 Taiwanese adults. Eur. J. Nutr. 2013, 52, 57-65. [CrossRef] [PubMed]

32. Lee, J.-W.; Lim, N.-K.; Baek, T.-H.; Park, S.-H.; Park, H.-Y. Anthropometric indices as predictors of hypertension among men and women aged 40-69 years in the Korean population: The Korean Genome and Epidemiology Study. BMC Public Health 2015, 15, 140. [CrossRef] [PubMed]

33. Tsai, P.-S.; Ke, T.-L.; Huang, C.-J.; Tsai, J.-C.; Chen, P.-L.; Wang, S.-Y.; Shyu, Y.-K. Prevalence and determinants of prehypertension status in the Taiwanese general population. J. Hypertens. 2005, 23, 1355-1360. [CrossRef] [PubMed]

34. Cirillo, M.; Laurenzi, M.; Trevisan, M.; Stamler, J. Hematocrit, blood pressure, and hypertension. The Gubbio Population Study. Hypertension 1992, 20, 319-326. [CrossRef] [PubMed]

35. Emamian, M.; Hasanian, S.M.; Tayefi, M.; Bijari, M.; Shafiee, M.; Avan, A.; Heidari-Bakavoli, A.; Moohebati, M.; Ebrahimi, M.; Darroudi, S. Association of hematocrit with blood pressure and hypertension. J. Clin. Lab. Anal. 2017. [CrossRef] [PubMed]

36. Singer, D.E.; Nathan, D.M.; Anderson, K.M.; Wilson, P.W.; Evans, J.C. Association of HbA1c with prevalent cardiovascular disease in the original cohort of the Framingham Heart Study. Diabetes 1992, 41, $202-208$. [CrossRef] [PubMed] 
37. Coresh, J.; Wei, G.L.; McQuillan, G.; Brancati, F.L.; Levey, A.S.; Jones, C.; Klag, M.J. Prevalence of high blood pressure and elevated serum creatinine level in the United States: Findings from the third National Health and Nutrition Examination Survey (1988-1994). Arch. Intern. Med. 2001, 161, 1207-1216. [CrossRef] [PubMed]

38. Chrysohoou, C.; Pitsavos, C.; Panagiotakos, D.B.; Skoumas, J.; Stefanadis, C. Association between prehypertension status and inflammatory markers related to atherosclerotic disease: The ATTICA Study. Am. J. Hypertens. 2004, 17, 568-573. [CrossRef] [PubMed]

39. Sparrow, D.; Weiss, S.T.; Vokonas, P.S.; Cupples, L.A.; Ekerdt, D.J.; Colton, T. Forced vital capacity and the risk of hypertension: The Normative Aging Study. Am. J. Epidemiol. 1988, 127, 734-741. [CrossRef] [PubMed]

40. Jacobs, D.R.; Yatsuya, H.; Hearst, M.O.; Thyagarajan, B.; Kalhan, R.; Rosenberg, S.; Smith, L.J.; Barr, R.G.; Duprez, D.A. Rate of Decline of Forced Vital Capacity Predicts Future Arterial Hypertension. Hypertension 2012, 59, 219-225. [CrossRef] [PubMed]

41. Wu, Y.; Vollmer, W.M.; Buist, A.S.; Tsai, R.; Cen, R.; Wu, X.; Chen, P.; Lai, Y.; Guo, C.; Mai, J.; et al. Relationship between lung function and blood pressure in Chinese men and women of Beijing and Guangzhou. Int. J. Epidemiol. 1998, 27, 49-56. [CrossRef] [PubMed]

42. Engström, G.; Wollmer, P.; Valind, S.; Hedblad, B.; Janzon, L. Blood pressure increase between 55 and 68 years of age is inversely related to lung function: Longitudinal results from the cohort study 'Men born in 1914'. J. Hypertens. 2001, 19, 1203-1208. [CrossRef] [PubMed]

43. Chobanian, A.V.; Bakris, G.L.; Black, H.R.; Cushman, W.C.; Green, L.A.; Izzo, J.L., Jr.; Jones, D.W.; Materson, B.J.; Oparil, S.; Wright, J.T., Jr. The seventh report of the joint national committee on prevention, detection, evaluation, and treatment of high blood pressure: The JNC 7 report. Jama 2003, 289, 2560-2571. [CrossRef] [PubMed]

44. Ma, M.; Tan, X.; Zhu, S. Prehypertension and its optimal indicator among adults in Hubei Province, Central China, 2013-2015. Clin. Exp. Hypertens. 2017, 39, 532-538. [CrossRef] [PubMed]

45. Jang, S.Y.; Ju, E.Y.; Choi, S.; Seo, S.; Kim, D.E.; Kim, D.-K.; Park, S.W. Prehypertension and obesity in middle-aged Korean men and women: The third Korea national health and nutrition examination survey (KNHANES III) study. J. Public Health 2012, 34, 562-569. [CrossRef] [PubMed]

46. Halloran, J. Classification: Naive Bayes vs. Logistic Regression. Available online: http://melodi.ee. washington.edu/ halloj3/pdfs/john (accessed on 8 November 2018).

47. Patil, T.R.; Sherekar, S. Performance analysis of Naive Bayes and J48 classification algorithm for data classification. Int. J. Comput. Sci. Appl. 2013, 6, 256-261.

48. Guyon, I.; Elisseeff, A. An introduction to variable and feature selection. J. Mach. Learn. Res. 2003, 3, 1157-1182.

49. Kohavi, R.; John, G.H. Wrappers for feature subset selection. Artif. Intell. 1997, 97, 273-324. [CrossRef]

50. Tayefi, M.; Esmaeili, H.; Saberi Karimian, M.; Amirabadi Zadeh, A.; Ebrahimi, M.; Safarian, M.; Nematy, M.; Parizadeh, S.M.R.; Ferns, G.A.; Ghayour-Mobarhan, M. The application of a decision tree to establish the parameters associated with hypertension. Comput. Methods Progr. Biomed. 2017, 139, 83-91. [CrossRef] [PubMed]

51. Ture, M.; Kurt, I.; Turhan Kurum, A.; Ozdamar, K. Comparing classification techniques for predicting essential hypertension. Expert Syst. Appl. 2005, 29, 583-588. [CrossRef]

52. Park, H.W.; Li, D.; Piao, Y.; Ryu, K.H. A Hybrid Feature Selection Method to Classification and Its Application in Hypertension Diagnosis. In Proceedings of the International Conference on Information Technology in Bio-and Medical Informatics, Lyon, France, 28-31 August 2017; pp. 11-19.

53. Li, D.; Park, H.W.; Ishag, M.I.M.; Batbaatar, E.; Ryu, K.H. Design and Partial Implementation of Health Care System for Disease Detection and Behavior Analysis by Using DM Techniques. In Proceedings of the 2016 IEEE 14th Intl. Conf. on Dependable, Autonomic and Secure Computing, 14th Intl Conf on Pervasive Intelligence and Computing, 2nd Intl. Conf. on Big Data Intelligence and Computing and Cyber Science and Technology Congress (DASC/PiCom/DataCom/CyberSciTech), Athens, Greece, 8-12 August 2016; pp. 781-786.

(C) 2018 by the authors. Licensee MDPI, Basel, Switzerland. This article is an open access article distributed under the terms and conditions of the Creative Commons Attribution (CC BY) license (http://creativecommons.org/licenses/by/4.0/). 